\title{
Economic Feasibility Evaluation of Microfiltration of Milk Prior to Cheesemaking
}

\author{
A. Papadatos, M. Neocleous, A. M. Berger, and D. M. Barbano' \\ Northeast Dairy Foods Research Center \\ Department of Food Science, \\ Cornell University, Ithaca, NY 14853
}

\section{ABSTRACT}

A nonlinear programming optimization model was used to evaluate the net revenues and potential profitability of microfiltration (MF) prior to cheesemaking in the 3-year period 1998 to 2000 , using monthly milk price and composition data. The model identifies the optimal mix of milk resources and determines if MF cheesemaking produces a higher net revenue than conventional cheesemaking that uses NDM and condensed milk for fortification. This study demonstrates the potential of this model to evaluate new technologies in cheese manufacture and improve decision making in the cheese industry. The use of MF produced higher net revenues in 30 out of the 36 mo for both Cheddar and low-moisture, part-skim mozzarella, leading to an appreciable increase in net revenue (vs. conventional cheesemaking) for both cheeses. The benefit from $\mathrm{MF}$ in net revenue was greater when the cream price was high. The use of $3 \mathrm{X}$ MF yielded the same net revenue as $2 \mathrm{X} \mathrm{MF}$. An estimate of manufacturing costs of $\mathrm{MF}$ vs. conventional cheesemaking was also made. To this end, the yields of products were calculated by the optimization model, while the production cost of each product was estimated from data of two economic engineering studies and a MF cheesemaking trial. The manufacturing cost of MF Cheddar was slightly higher than the manufacturing cost of conventional Cheddar. However, the benefit in net revenue from the use of MF was estimated to be higher than the difference in manufacturing costs. Moreover, some advantages in the new coproducts of MF Cheddar could outweigh its higher manufacturing cost. The relationships between prices and recoveries of coproducts required to render $\mathrm{MF}$ profitable were identified.

(Key words: cheese, optimization, microfiltration)

Received August 8, 2002.

Accepted November 18, 2002.

Corresponding author: D. M. Barbano; e-mail: dmb37@cornell.edu.

${ }^{1}$ Use of names, names of ingredients, and identification of specific models of equipment is for scientific clarity and does not constitute any endorsement of product by authors, Cornell University, and the Northeast Dairy Foods Research Center.
Abbreviation key: ACONST2 = the proportion of lactose, NPN, and minerals that should be retained during ultrafiltration of the MF permeate, $\mathbf{C F}=$ concentration factor, FATCREAM = percent of fat in cream, FATSKIM = percent of fat in skim milk, FATWHOLE = percent of fat in raw milk, FDB = fat on a dry basis, LACRET = amount of lactose in the retentate, LACSKIM = amount of lactose in skim milk, LACWHOLE = percent lactose in raw milk, LPREC2 $=$ percent recovery of lactose from the UF permeate from SPC production in lactose powder, MAXWHOLE = maximum amount of raw milk allowed, $\mathbf{M F}=$ microfiltration, $\mathbf{M I}$ NRET = amount of minerals in the retentate, MINSKIM = amount of minerals in skim milk, NPNRET $=$ amount of NPN in the retentate, NPNSKIM $=$ amount of NPN in skim milk, NPNWHOLE = percent of NPN in raw milk, PROPCAS = percent of casein in total protein, PROTSKIM = percent of total protein in skim milk, SPC = serum protein concentrate, $\mathbf{T P R E C}=$ percent recovery of whey protein concentrate, TRPROTRET = amount of true protein in the retentate, TRPROTSKIM = amount of true protein in skim milk, WPC $=$ whey protein concentrate.

\section{INTRODUCTION}

Membrane filtration processes are not new in the cheese industry. Ultrafiltration of milk prior to cheesemaking has been widely used (Cheryan, 1998). It markedly increases cheese yield by retaining whey proteins in the cheese but it has been shown to cause textural and flavor defects (Jameson and Lelievere, 1996) in Cheddar and mozzarella cheeses, largely due to the retention of whey proteins (Bech, 1993). On the other hand, MF of skim milk prior to cheesemaking offers the advantage that milk serum proteins permeate the membrane and hence they are not retained in the cheese, while caseins are retained. Consequently, the use of MF retentate leads to composition very similar to that of conventional cheese curd. While MF is not expected to increase cheese yield, it will increase utilization of plant capacity and amount of cheese produced 
per day and reduce the amount of rennet used (Neocleous et al., 2001).

Another advantage of MF is the potential of the MF permeate from skim milk, which is free of bacteria, rennet and starter. The MF permeate can be ultrafiltered to produce high-quality serum protein concentrate (SPC) (Maubois, 1997). Since the MF permeate is sterile, it does not need to be pasteurized, opposite to whey, which is very perishable and hence needs to be pasteurized. Pasteurization of whey partly denatures serum proteins, thus impairing their functionality. Moreover, the MF permeate from skim milk has minimal amount of fat (i.e., $<0.01 \%$ ) and hence the SPC from MF has superior functional properties, compared to whey protein concentrate (WPC) (Rosenberg, 1995), which typically has $4 \%$ fat (Huffman, 1996).

The main reason for the lack of attention to MF so far has been the problem of fast fouling of MF membranes due to the high permeation fluxes (Horton, 1997). However, the patent of Alfa Laval which achieved uniform and low transmembrane pressure, created by a cocurrent circulation of the MF permeate to the feed, greatly reduces fouling (Maubois, 1997). Thus, many authors (Mistry and Maibois, 1993, Rosenberg, 1995) have claimed that MF prior to cheesemaking will become a widely used method in the near future, but data on the economic feasibility of the process has been lacking.

In our study, a nonlinear programming optimization model is used to evaluate the economics of MF prior to cheesemaking with respect to the ingredient cost. Mathematical programming has been widely used to optimize blending of ingredients in food applications (Bender et al., 1982) but little work has been done for the cheese industry. Kerrigan and Norback (1986) developed a linear programming model to maximize net revenue in Cheddar cheese production. Their model was simple, using only the available milk resources as decision variables and having only four constraints. Another linear programming model (Craig et al., 1989) was developed to maximize net revenue in Process cheese manufacture. Both of these models used the Van Slyke cheese yield formula and did not account for any coproducts produced from the processing of separated whey. The first model to include coproducts produced from separated whey was developed by Samakidis (1994), who was also the first to use the nonlinear Barbano yield formula (Barbano, 1996) to estimate cheese yield. However, the model was maintained linear through the application of iterations until the nonlinear equation was satisfied. Since the model was linear, assumptions were made for the composition of whey to estimate the yields of coproducts.
Papadatos et al. (2002) reported for first time the use of a nonlinear optimization model for determination of the optimal mix of milk resources to be used for cheesemaking. The model identifies the optimal mix of milk resources and types of cheeses and coproducts that maximize net revenue in cheese manufacture. The selection of a nonlinear model has the advantage that the yield equations are valid under any composition range of the standardized milk, opposed to the models mentioned above. The model presented in this paper allows the option of MF of milk prior to cheesemaking while it also accounts for the coproducts produced from the MF permeate and is an extension of the model described previously (Papadatos et al., 2002).

The goal of our research was to evaluate the economic feasibility of using MF of skim milk prior to Cheddar and mozzarella cheese manufacture. The analysis in this study was divided into two problems. In problem 1 , the impact of variation in prices of resources and milk composition on the profitability of MF prior to cheesemaking was determined. The optimization model was used to determine the optimal mix of resources and whether MF produced higher net revenues than conventional cheesemaking in every month from January 1998 to December 2000. The impact of a higher CF (3X) $\mathrm{MF}$ on net revenue was also determined. Moreover, since some cheese plants might prefer purchasing MF retentate to microfiltering milk in the plant, an estimation of the price of MF retentate was attempted, based on the value of the raw milk microfiltered and the value of the coproducts derived from the MF permeate. In problem 2, the impact of MF on the milk-based ingredient cost (i.e., problem 1) was neglected and a comparison of manufacturing costs of MF cheesemaking vs. conventional cheesemaking was made. For this problem, the optimization model was not used in its normal function (i.e., optimizing) but it was used to calculate the yields of Cheddar cheese and coproducts for both conventional and MF Cheddar.

\section{MATERIALS AND METHODS}

\section{Software/Programming Environment}

Excel. The optimization model works in Excel (Microsoft, Seattle, WA). A program was written in Visual Basic (Microsoft, Seattle, WA), which converts the data specified by the user to a mathematical programming model. More specifically, the program specifies the objective function, builds the constraints, and calls the solver of Excel. In addition, after the solver has identified the optimal solution to the problem, the code converts this solution to organized reports to help the user evaluate the results.

Journal of Dairy Science Vol. 86, No. 5, 2003 
Solver. The nonlinear optimization model is solved with the Premium Solver (Frontline Systems, Inc., Incline Village, NV), which is an enhanced version of the default solver of Excel, with greater speed and precision, and ability to handle large-scale problems (Frontline Systems, Inc., 1999). It uses the generalized reduced gradient method to solve nonlinear problems, such as the one presented in our model. The options, which are specified by the user, were set as follows: iterations: 1000 , precision: 0.00001 , convergence: 0.001 , estimates: tangent, derivatives: forward, and search: Newton.

\section{Options Provided by the Model}

Resources. The user can specify any number of resources, and the price and composition of each resource. In the description of the model provided below, for simplicity only three resources are used. The user can specify any batch size of standardized milk. Regardless of the batch size specified, the model solves the problem on a basis of $100 \mathrm{lb}$ and then calculates and reports the results for the specified batch size. This saves the nonlinear models from solving difficulties that are due to poor scaling. When NDM is included in the resources, the user is allowed to choose if NDM will be reconstituted in milk or in water. If NDM is reconstituted in water, the user must specify the percentage total solids after reconstitution. The user must also choose if cream removal is permitted from each whole milk included in the resources.

Cheese. The user must specify the target moisture, salt, fat on a dry basis (FDB) (minimum and maximum), the retention coefficients in the selected yield formula, and the maximum cheese yield allowed. The maximum cheese yield allowed should reflect the maximum capacity (in pounds per hundred pounds of standardized milk) of the cheesemaking equipment.

Coproducts. Whey is always separated into whey cream and separated whey. The fat content of both must be specified by the user. Different types of coproducts can be produced from separated whey. The user must choose between liquid separated whey and any combination of whey powder, WPC and lactose powder. The model will select the type and amount of coproducts to maximize net revenue. One or more of the coproducts allowed by the user may be produced in the optimal solution. When raw milk is microfiltered, there are also some other coproducts produced, i.e., cream removed from that raw milk and SPC and lactose powder, which result from the ultrafiltration of the MF permeate. In all cases some waste is generated, which has a cost $(\$ /$ lb solids) of disposal that is specified by the user. For each coproduct the user must specify the price and mois- ture content. For WPC and SPC, the protein content must also be specified. The user must also specify five recovery factors, i.e., the percent recovery of fat from whey, the percent recovery of separated whey, the percent recovery of WPC and SPC (TPREC), the percent of lactose in the UF permeate from separated whey that is recovered in lactose powder, and the percent of lactose in the UF permeate from the MF permeate that is recovered in lactose powder (LPREC2). Hurst et al. (1990) suggested an $80 \%$ recovery for WPC, while Guu and Zall (1992) reported a $62 \%$ recovery of lactose in lactose powder. These are the values used in this study.

$\boldsymbol{M F}$. The user must decide whether to allow the option of $\mathrm{MF}$ of raw milk. If $\mathrm{MF}$ of raw milk is allowed as an option, then the concentration factor (CF), the percent of fat in the cream removed from that raw milk (FATCREAM), and the percent of fat in skim milk (FATSKIM) must be specified. If MF is allowed as an option, the user must also decide whether to allow diafiltration of the MF retentate, in which case the diafiltration factor (i.e., ratio of weight of water to weight of retentate) must be specified.

\section{Description of the Model}

Objective function. A mathematical programming model identifies the set of variables (vector $\mathrm{X}$ ) that maximize the objective function $\mathrm{Z}=\mathrm{c} \times \mathrm{X}$ under a set of constraints described by $\mathrm{A} \times \mathrm{X} \leq \mathrm{b}$. The objective function of this model is the net revenue, i.e., the difference between the revenue from cheese and coproducts minus the cost of resources.

Decision variables. The nonlinear optimization model for conventional cheesemaking has already been described (Papadatos et al., 2002). The model presented in this paper is modification of the nonlinear optimization model with some additional variables and constraints to allow the possibility of MF of milk prior to cheesemaking versus conventional cheesemaking. In addition, some of the constraints of the initial model have been slightly modified.

Variables $\mathrm{x} 1$ to $\mathrm{x} 30$ were defined previously (Papadatos et al., 2002). The new variables, which all represent weights, include the weight of raw milk that is microfiltered (x31), weight of total solids in SPC (x32), weight of total solids in lactose powder from the MF permeate (x33), and weight of cream removed from the raw milk that is microfiltered (x34). Introducing variable x31 means that the enhanced model has two variables for the same milk resource (raw milk), i.e., $x 4$ represents the amount of raw milk that is not microfiltered, while $\mathrm{x} 31$ is the amount of the same raw milk that is microfiltered. 
Constraints. All the new constraints share a common concept. Each pound of raw milk that is microfiltered corresponds to a certain amount of each coproduct (i.e., removed cream, SPC, and lactose powder). Therefore, all three new constraints have the form:

$$
\begin{gathered}
\text { Amount of coproduct }(\mathrm{x} 32 \text { or } \times 33 \text { or } \times 34) \\
-(\text { coefficient }) \times \times 31=0
\end{gathered}
$$

The coefficient is different for each constraint. In order to calculate each coefficient, it has been assumed that all fat and casein are fully retained during $\mathrm{MF}$ of skim milk and that the concentration of all water-soluble components (serum proteins, lactose and NPN) in the nonfat, noncasein portion of the MF retentate equals their concentration in the nonfat, noncasein portion of the MF permeate. The same is applied for minerals but it is also taken into account that a portion of minerals (micellar calcium phosphate) is fully retained. The concentration of calcium and phosphorus in skim milk are assumed to be $0.15 \%$ and $0.20 \%(\mathrm{w} / \mathrm{w})$, respectively. Two thirds of calcium and half of phosphorus are bound to casein (Lucey and Fox, 1993). When the above assumptions are applied, the coefficients become a function of only the composition of the raw milk, the percent fat in cream and skim milk, and the concentration factor. Since all these are specified by the user, the new constraints are linear. The new constraints are:

\section{Yield of cream}

The portion of raw milk that is microfiltered (x31) is initially separated into cream and skim milk and only the skim milk is microfiltered. The amount of cream separated from the portion of raw milk that is microfiltered depends on the percent fat in raw milk (FATWHOLE), skim milk, and cream:

$$
\begin{gathered}
\text { x34 - (FATWHOLE }- \text { FATSKIM }) /(\text { FATCREAM } \\
- \text { FATSKIM }) \times \text { x31 }=0
\end{gathered}
$$

\section{SPC yield}

The yield of SPC is calculated with the same formula as that used for the WPC yield but the formula uses the composition of the MF permeate instead of the composition of separated whey. Therefore, the SPC yield depends on the amounts of true protein in the skim (TRPROTSKIM), true protein in the retentate (TRPROTRET), lactose in the skim (LACSKIM), lactose in the retentate (LACRET), NPN in the skim (NPNSKIM), NPN in the retentate (NPNRET), minerals in the skim (MINSKIM) and minerals in the retentate (MINRET). It also depends on the proportion of lactose, NPN, and minerals that should be retained during ultrafiltration of the MF permeate (ACONST2).
The percent recovery of SPC is assumed to be equal to that of WPC.

$$
(1 /(\text { TPREC } / 100)) \times x 32=(\text { TRPROTSKIM }-
$$
TRPROTRET $)+$ ACONST2 $\times(($ LACSKIM - LACRET $)$

$$
\begin{aligned}
& +(\text { NPNSKIM - NPNRET }) \\
& +(\text { MINSKIM - MINRET })
\end{aligned}
$$

The amount of each component in the skim milk is calculated so that its concentration is the same in the nonfat portion of the skim milk and of the raw milk. For instance, the amount of NPN in the skim milk is related to the percent of NPN in raw milk (NPNWHOLE) as:

$$
\begin{gathered}
\text { NPNSKIM }=\text { NPNWHOLE } /(100-\text { FATWHOLE }) \\
\times(100-\text { FATSKIM }) / 100 \times(x 31-x 34)
\end{gathered}
$$

The amount of each component in the MF retentate is calculated so that its concentration in the nonfat, noncasein portion of the MF retentate and MF permeate is the same. The percent of casein in the skim milk is calculated as the total protein percent in skim milk (PROTSKIM) multiplied by the percent of casein in total protein (PROPCAS). Therefore, the amount of NPN in the MF retentate is

$$
\begin{gathered}
\text { NPNRET }=\text { NPNSKIM } /(1-\text { FATSKIM } / 100 \\
- \text { PROPCAS } / 100 \times \text { PROTSKIM } / 100) \times((\text { x31 } \\
- \text { x34 }) / C F-\text { FATSKIM } / 100 \times(\mathrm{x} 31-\mathrm{x} 34) \\
- \text { PROPCAS } / 100 \times \text { PROTSKIM } / 100) \times(\mathrm{x} 31-\mathrm{x} 34))
\end{gathered}
$$

After the amount of each component in the skim milk and in the MF retentate has been calculated as described above, the SPC yield is a function of only the raw milk composition, the fat content of skim milk and cream, and the concentration factor.

\section{Yield of lactose powder from the MF} permeate

The formula is similar to the one that calculates the yield of lactose powder from the separated whey (Papadatos et al., 2002). The yield of lactose powder from the MF permeate depends on the amount of lactose in the skim milk and in the retentate and on the percent recovery of lactose in lactose powder. The user can specify a different lactose recovery for the lactose powder derived from the MF permeate versus the lactose powder derived from separated whey. This option is given because the recovery of lactose crystals from the UF permeate of MF permeate is expected to be higher than from the UF permeate of separated whey.

$$
\begin{gathered}
(1 /(\mathrm{LPREC} 2 / 100)) \times \times 33=(1-\mathrm{ACONST} 2) \\
\times(\mathrm{LACSKIM}-\mathrm{LACRET})
\end{gathered}
$$


The amount of lactose in the skim milk, which is calculated from the percent lactose in raw milk (LACWHOLE), and the amount of lactose in the MF retentate are calculated in the way described for NPN in the SPC yield constraint. Thus the yield of lactose powder from the MF permeate can be written as:

$$
\begin{gathered}
(1 /(\text { LPREC } 2 / 100)) \times \mathrm{x} 33=(1-\text { ACONST } 2) \\
\times(\text { LACWHOLE } /(100-\text { FATWHOLE }) \times(100 \\
- \text { FATSKIM }) / 100-\text { LACWHOLE } /(100 \\
- \text { FATWHOLE }) \times(100-\text { FATSKIM }) / 100 /(1 \\
- \text { FATSKIM } / 100-\text { PROPCAS } / 100 \times \text { PROTSKIM } / 100) \\
\times(1 / \text { CF }- \text { FATSKIM } / 100-\text { PROPCAS } / 100 \\
\times \text { PROTSKIM } / 100)) \times(\mathrm{x} 31-\mathrm{x} 34)
\end{gathered}
$$

Apart from these new constraints, there are also a few constraints of the initial model which have been modified.

1. Batch size of standardized milk (constraint 1 from Papadatos et al., 2002)

The sum of the amounts of resources should equal the batch size. Therefore, the sum of the amounts of raw milk that is not microfiltered (x4), NDM, and MF retentate minus the amount of cream removed from the raw milk that is not microfiltered should equal the batch size. Each pound of raw milk that is microfiltered yields (FATCREAM - FATWHOLE)/(FATCREAM FATSKIM)/CF pounds of retentate. Therefore, the constraint can be written as:

$$
\begin{gathered}
-\mathrm{x} 1+\mathrm{x} 4-\mathrm{x} 5+\mathrm{x} 6+(\text { FATCREAM } \\
- \text { FATWHOLE }) /(\text { FATCREAM }- \text { FATSKIM }) / C F) \\
\times \mathrm{x} 31=0
\end{gathered}
$$

\section{Amount of waste solids (constraint 19 from Papadatos et al., 2002)}

In this constraint, which determines the amount of waste solids generated, the amount of waste contributed by the MF permeate has to be added. This includes the NPN and minerals of the MF permeate that are not retained in the SPC, and the amount of SPC that is not recovered. Therefore, the additional amount of waste is:

$$
(1 \text { - ACONST2 }) \times((1-\text { LPREC2 }) \times(\text { LACSKIM }
$$
- LACRET $)+($ NPNSKIM - NPNRET $)+($ MINSKIM

- MINRET $))+(1-($ TPREC/100) $) /($ TPREC/100 $) \times x 32$

\section{Upper limit on the amount of raw milk}

The constraint that limits the amount of raw milk used has been modified to restrict the sum of raw milk nonmicrofiltered plus raw milk microfiltered. This has to be less than the maximum amount of raw milk allowed (MAXWHOLE) by the user.

\section{$\mathrm{x} 4+\mathrm{x} 31 \leq$ MAXWHOLE}

Linear vs. nonlinear model. In a linear programming model, all the elements of the matrix $\mathrm{A}$ and the vectors $b$ and $c$ are pure numbers, while in a nonlinear programming model some of the elements depend on the value of at least one variable. The advantage of a linear programming model is the existence of a standard solving procedure, the Simplex method (Hillier and Lieberman, 1995), which guarantees to identify the global optimum of any linear model. On the other hand, there is no method that guarantees to identify the global optimum of all nonlinear models, for most of which only a local optimum can be found. Most algorithms for nonlinear models require a starting vector $\mathrm{X}$ and the local optimum they find markedly depends on this starting vector. To overcome this difficulty, the model presented here first approximates the solution of each problem with a linear model and then uses the solution of the linear model as a starting point for the nonlinear model. In this way, the initial vector $\mathrm{X}$ is very likely to be sufficiently close to the global optimum of the nonlinear model so as to ensure that the solution provided to the user is a global optimum.

Reports produced. A code has been developed to convert the solution identified by the solver to organized reports in order to help the user evaluate the results. There are five different reports produced, which have been described previously (Papadatos et al., 2002). The flow report shows the amount of each product and the weight of each milk solids component included in each product. The composition report shows the concentration of each component in the standardized milk and in each product and the optimal FDB for the cheese. The cost-revenue report shows the contribution of each milk resource to cost, the contribution of each product to revenue, and the net revenue. The mass balance report checks the mass balance of each component among the resources and the products to ensure that the model has identified a solution that maintains mass balance. Finally, the sensitivity analysis report indicates the magnitude of changes in prices that does not alter the optimal milk resources and type of coproduct. Since sensitivity analysis is a characteristic of linear models, the solution of our nonlinear model is first linearized in order to perform sensitivity analysis.

\section{Design of the Analysis}

The analysis was divided into two problems. In problem 1 , the impact of variation in milk resource prices and composition on the net revenues when MF was available as an option prior to cheesemaking was determined. The nonlinear optimization model was used to 
Table 1. Parameters used in problem 1.

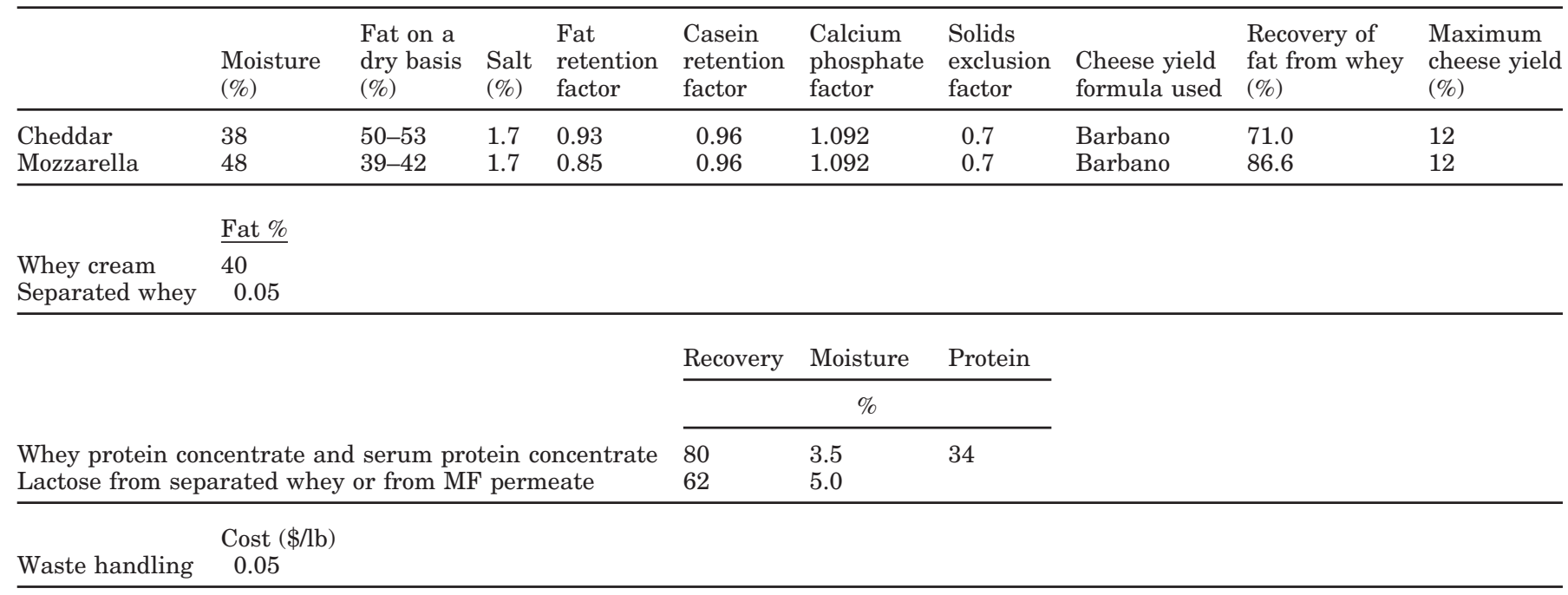

determine the optimal mix of resources and whether MF led to a higher net revenue than conventional cheesemaking in every month from January 1998 to December 2000. Four milk resources were available: raw milk, fresh cream, condensed skim milk (34\% solids) and NDM (96.5\% solids). Cream removal from raw milk was allowed. The option of $2 \mathrm{X} \mathrm{MF}$ of raw milk was allowed. If the model chose to microfilter raw milk, it would first separate it into cream and skim milk and would microfilter only the skim milk. Diafiltration of the MF retentate was not allowed. The only coproducts produced from separated whey were $34 \%$ WPC and lactose powder. The values of the other parameters used are given in Table 1.

The impact of a higher CF (3X) MF on net revenue was also determined. In addition, since some cheesemakers may choose to purchase MF retentate from another factory rather than microfilter milk in the plant, it was of interest to determine the price of MF retentate purchased from another factory that would achieve the same net revenue as the use of MF in the cheese plant prior to cheesemaking. To calculate the price of MF retentate, it was assumed that the value of raw milk separated and microfiltered was equal to the value of the MF retentate and the coproducts (i.e., cream removed from the raw milk microfiltered, SPC, and lactose powder) minus the handling cost of waste from the MF permeate. The yields and prices of the coproducts produced from the MF permeate in each month were used. Moreover, by adding the economic benefit from the use of MF in each month to the value of the raw milk separated and microfiltered, the price of $2 \mathrm{X} \mathrm{MF}$ retentate (produced at another factory) that would make its use produce the same net revenue as the use of conventional resources was calculated in each month.
In problem 2, an estimate of manufacturing costs of MF cheesemaking vs. conventional cheesemaking was made. In MF cheesemaking, the MF plant separates raw milk into cream and skim milk and microfilters only the skim milk to produce MF retentate and MF permeate. The MF permeate is further processed to produce $34 \%$ SPC and lactose powder, while the MF retentate is used for cheesemaking. Therefore, the MF permeate has no relation to the cheesemaking plant, which means that the coproducts from the MF permeate (i.e., SPC and lactose) are produced independently of the cheesemaking process. This is a different concept from conventional cheesemaking, in which the coproducts are produced from the whey that comes from the cheese vat.

The total manufacturing costs for the two scenarios (conventional vs. MF cheesemaking) were compared on a basis of $200 \mathrm{lb}$ raw milk. The optimization model was used to calculate the yields of Cheddar cheese and coproducts for both conventional and MF Cheddar. This was achieved by restricting the resources so that the model could use only a certain resource at a time. More specifically, in one case the model was forced to use $200 \mathrm{lb}$ raw milk for conventional Cheddar, while in the second case it was forced to microfilter 200 lb raw milk. Therefore, for this problem the model was not used in its normal function (i.e., optimizing) but it was used to calculate yields.

\section{Prices and Composition of Milk Resources}

The prices and composition of milk resources used for problem 1 in this study have been described in a previous study (Papadatos et al., 2002). The prices of milk resources refer to the Northeast area of the United 
States for the 3-year period 1998-2000, while the prices of Cheddar and coproducts were Midwest prices, as there was no Northeast price quoted. The price of lowmoisture, part-skim mozzarella was assumed to equal that of Cheddar, the price of $34 \%$ SPC was set equal to the price of $34 \%$ WPC, and the price of lactose produced from the UF permeate from SPC production was set equal to the price of lactose produced from WPC production from separated whey. The milk composition data refer to the Northeast area for year 2000. The fat content of removed and added cream was set at $40 \%$ at all times, while the nonfat portion of cream varied according to the raw milk composition. In addition, the nonfat portion of condensed skim varied according to the raw milk composition, while the composition of NDM was assumed to be constant throughout the whole 3 -year period and was derived from the average composition of raw milk.

\section{Manufacturing Costs}

For problem 2, the manufacturing costs for the production of Cheddar cheese (Mesa-Dishington et al., 1987) and WPC (Hurst et al., 1990) were taken from two economic engineering studies, while the production cost of SPC and the cost of MF of skim milk were estimated from the cost of ultrafiltration in WPC production. A $2 \mathrm{X} \mathrm{CF}$ was selected for MF to illustrate the direction and possible magnitude of the impacts of $\mathrm{MF}$ on manufacturing costs. Changes in nonmilk ingredient use (e.g., rennet) and other components of manufacturing cost were estimated from the MF cheesemaking trials reported by Neocleous et al. (2002). In order for the two scenarios (conventional vs. MF Cheddar) to be comparable, the capacity of the conventional plant was doubled and costs were reduced due to economies of scale (Mesa-Dishington et al., 1987) so that each type of cheesemaking was producing the same amount of cheese per day.

\section{RESULTS AND DISCUSSION}

\section{Problem 1. Comparison of Net Revenue for Conventional vs. MF Cheesemaking Based on Ingredient Cost}

Impact of MF on net revenue. The net revenue markedly varied in the 3-year period studied for both Cheddar (Table 2) and low-moisture, part-skim mozzarella (Table 3). The net revenue for Cheddar varied from $\$-0.01$ to $\$ 5.23$ per $100 \mathrm{lb}$ standardized milk, while the net revenue for mozzarella varied from $\$ 1.80$ to $\$ 9.52$ per $100 \mathrm{lb}$ standardized milk.

MF produced higher net revenues than other ingredient strategies in 30 out of the 36 mo for both cheeses, leading to an average increase (versus no MF) in net revenue for the 3-year period of $\$ 0.41$ for Cheddar and $\$ 0.45$ for mozzarella per $100 \mathrm{lb}$ standardized milk. These increases can translate to $\$ 8200$ and $\$ 9000$ per day, respectively, for a cheese plant that processes 2,000,000 lb standardized milk per day.

Another benefit from the use of MF was that it rendered the maximum cheese yield allowed (i.e., 12\%) optimal in all months, while the maximum yield was optimal in only half of the months for Cheddar when MF was not available as an option (Papadatos et al., 2001). Maximizing cheese yield may have a positive economic impact by increasing the efficiency of a cheese plant and diluting some fixed costs to more pounds of cheese, thus reducing the average cost per pound of cheese. Since maximizing cheese yield was optimal for mozzarella even when MF was not available as an option, this benefit from MF may be more important for Cheddar.

Factors that influenced the benefit of MF. The benefit in net revenue from MF (versus no MF) was greater in the months in which the cream price was high and the value of the nonfat portion of raw milk was low (Figure 1). This would be expected, since the MF retentate was the lowest-cost source of concentrated nonfat milk solids for the cheese in those months. The use of MF also shifted the choice of the optimal FDB from the high end to the low end in some months (May 1998 and 2000, June 1998, 1999, and 2000, and August 2000 for both cheeses). This means that MF rendered the nonfat portion of raw milk more attractive to incorporate in the cheese than the fat portion in those months. The benefits of MF in net revenue for the two cheeses followed each other closely (Figure 2). In the months (e.g., May 1998) with very low value of the nonfat portion of raw milk, the benefit of MF of milk prior to cheesemaking in net revenue for mozzarella was much higher than the benefit for Cheddar.

MF led to lower net revenues in only 6 mo, which were the months with the highest value in the nonfat portion of raw milk. In those months, double standardization with cream and either NDM or condensed skim was optimal and led to the choice of the high end of FDB range. In those months, reconstitution of NDM with water to replace part of the skim portion of raw milk would markedly increase net revenue (Papadatos et al., 2002). Therefore, a strategy that would produce high net revenues for a cheese plant would be to MF milk in all months except for those with a high value in the nonfat portion of raw milk, in which the use of NDM reconstituted with water at low solids would be optimal. Condensed skim could be excluded from the resources in all months. 
Table 2. Amounts of milk resources used for Cheddar (lb/100 lb standardized milk), theoretical cheese yield (lb/100 lb standardized milk), fat on a dry basis (FDB) in the cheese, and net revenue (dollars/100 lb standardized milk) when $\mathrm{CF}=2 \mathrm{X}$ microfiltration was allowed as an option for each month for the period from January 1998 to December 2000.

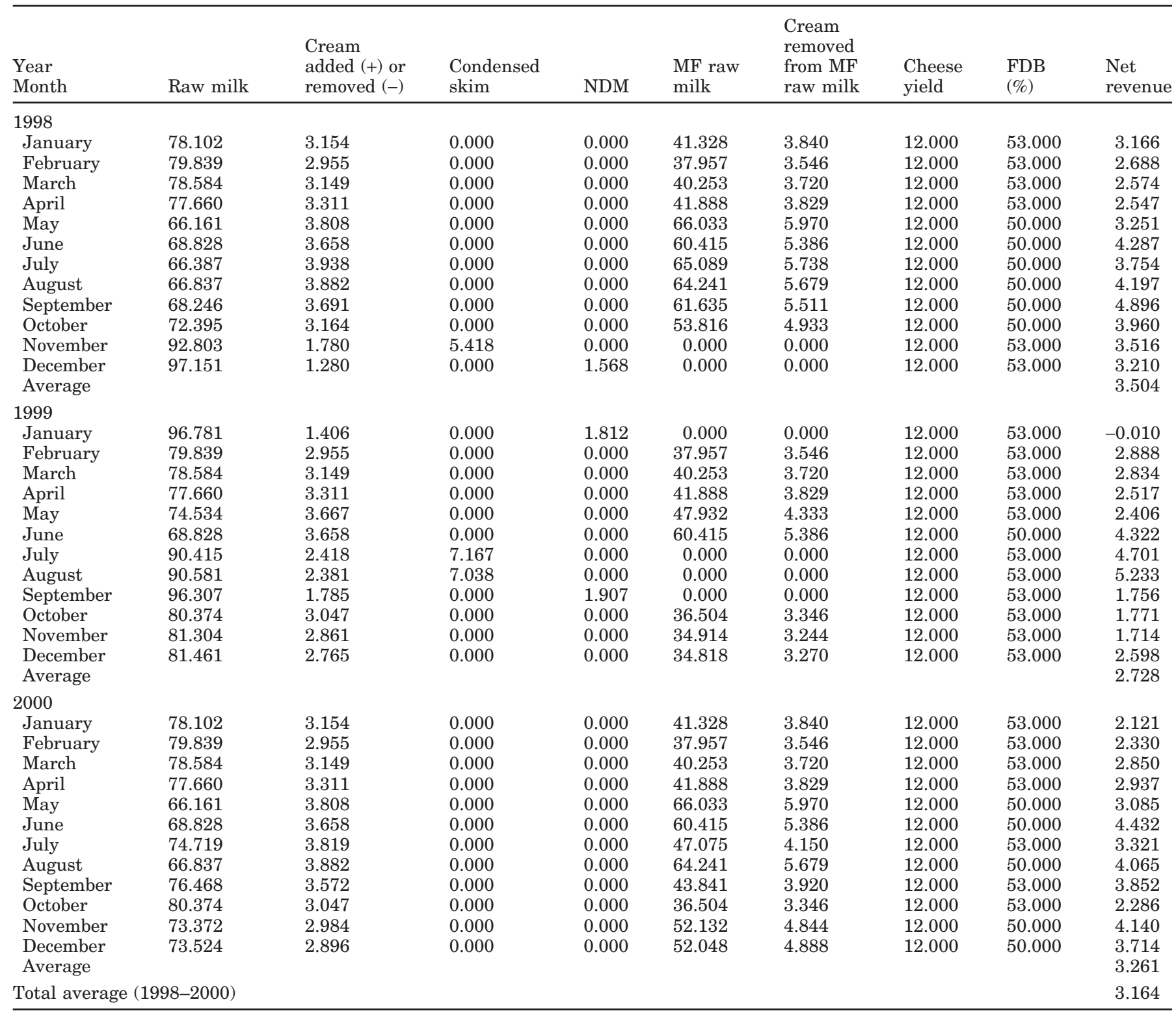

Sensitivity analysis on the benefit of MF. In this problem, the selling price of $34 \% \mathrm{SPC}$ was set equal to the price of $34 \% \mathrm{WPC}$ and the percent recovery of lactose from SPC production was set equal to the percent recovery of lactose from WPC production. However, in reality the $34 \%$ SPC price is likely to exceed the $34 \%$ WPC price and the recovery of lactose crystals from the UF permeate from SPC production is likely to be higher than the recovery of lactose from the UF permeate from WPC production. Therefore, the increases in net revenue that result from the use of MF prior to cheesemaking may become even higher in real situations. Since the average yield of 34\% SPC for both cheeses was approximately $0.22 \mathrm{lb} / 100 \mathrm{lb}$ standardized milk, every $\$ 0.10$ advantage in SPC price vs. WPC price would increase net revenue by $\$ 0.02$ per $100 \mathrm{lb}$ standardized milk.

Sensitivity analysis was performed to identify the maximum processing cost of $\mathrm{MF}$ in each month that would still allow MF to achieve a higher net revenue than conventional cheesemaking. The average allowable processing cost for MF in the 3-year period was $\$ 0.75$ per $100 \mathrm{lb}$ raw milk separated and processed by MF. Since the average amount of raw milk microfiltered 
Table 3. Amounts of milk resources used for mozzarella (lb/100 lb standardized milk), theoretical cheese yield (lb/100 lb standardized milk), fat on a dry basis (FDB) in the cheese, and net revenue (dollars/100 lb standardized milk) when $\mathrm{CF}=2 \mathrm{X}$ microfiltration was allowed as an option for each month for the period from January 1998 to December 2000.

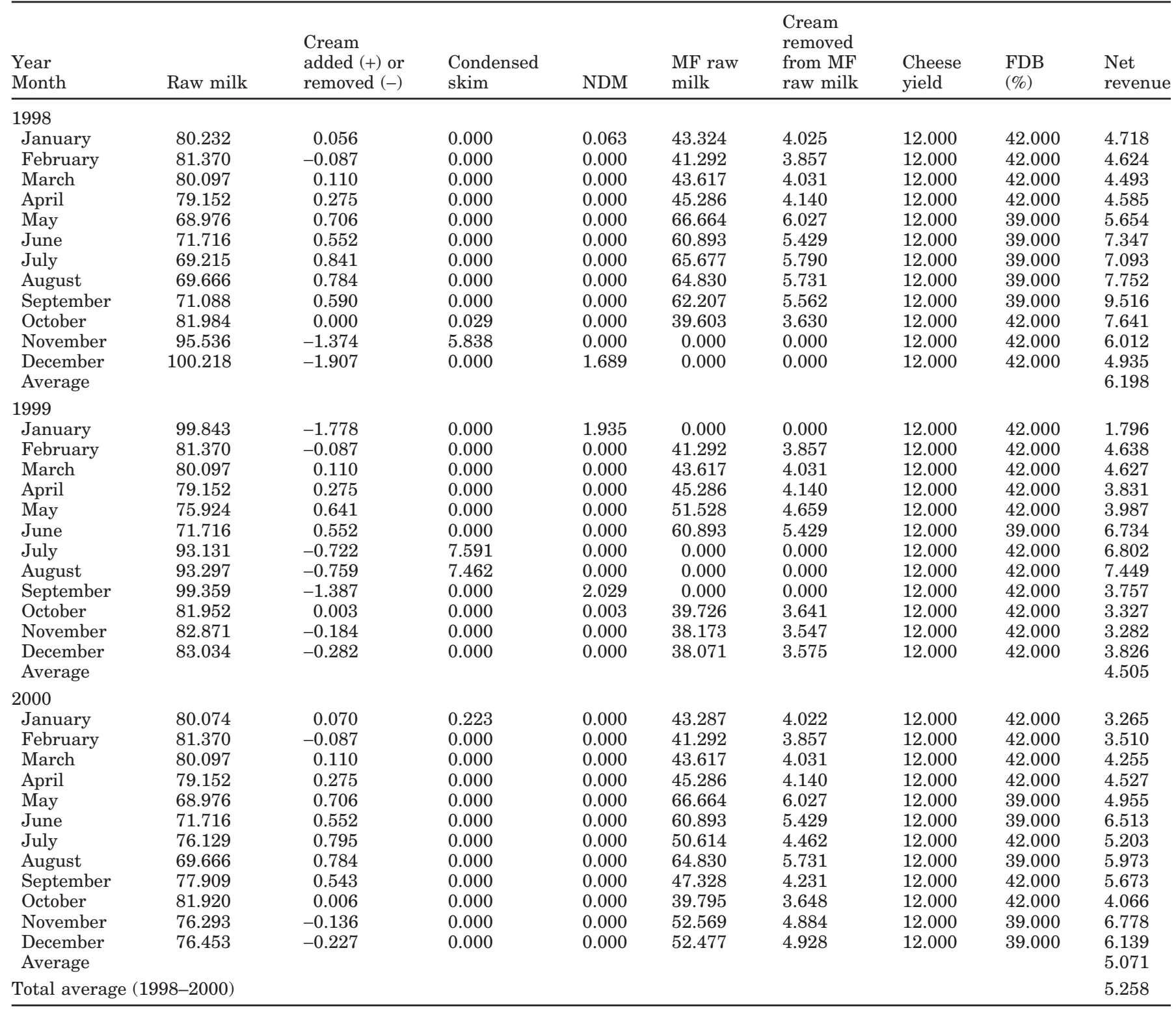

in the 30 mo in which $\mathrm{MF}$ was optimal was about 48 $\mathrm{lb}$, the above allowable processing cost would translate to about $\$ 0.36$ per $100 \mathrm{lb}$ standardized milk.

Effect of $\mathrm{CF}$ on net revenue. When $3 \mathrm{X} \mathrm{MF}$ was examined as an option (results not shown), it gave the same net revenue as the $2 \mathrm{X} \mathrm{MF}$ for both cheeses in all months. Since higher CF implies higher processing cost, it can be concluded that $2 \mathrm{X}$ is more attractive than $3 \mathrm{X}$. One could claim that if SPC price was set higher than WPC price, there would be some benefit from $3 \mathrm{X} \mathrm{MF}$, since higher CF increases SPC yield and reduces WPC yield. However, the SPC yield was the same in all months for both concentration factors because less milk was being microfiltered in the case of $3 \mathrm{X}$ in order not to exceed the maximum cheese yield allowed. More specifically, in all months the amount of raw milk microfiltered at $3 \mathrm{X}$ was exactly $75 \%$ of the amount of raw milk microfiltered at $2 \mathrm{X}$, which led to the same SPC yield for both concentration factors. Even when the two concentration factors were compared at a higher maximum cheese yield (14\%), they gave the same net revenue in all months.

The above conclusions hold true as long as the maximum cheese yield (i.e., lb per 100 lb standardized milk) 


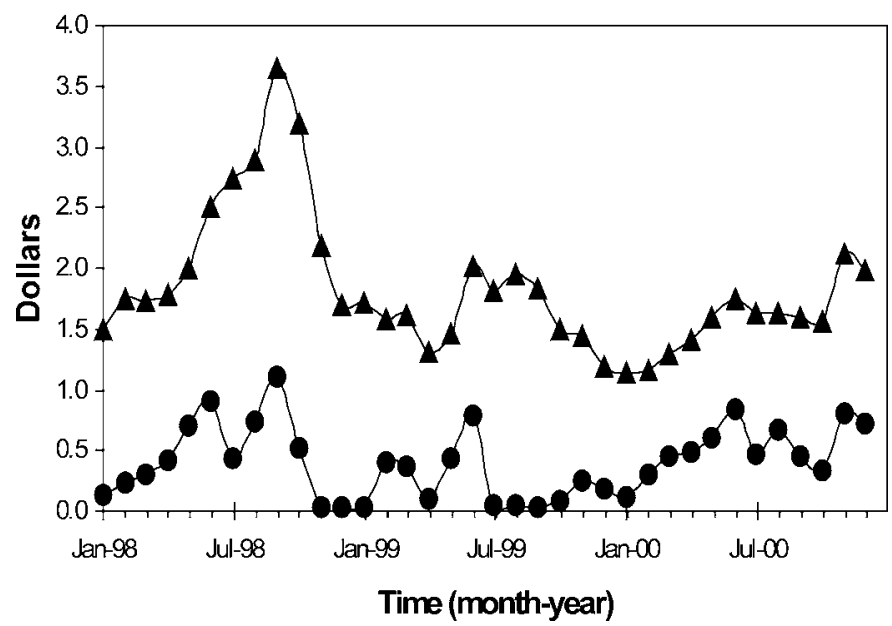

Figure 1. Benefit in net revenue (dollars/100 lb standardized milk) from microfiltration (versus conventional cheesemaking) for Cheddar $(-)$ and Class II price (dollars/lb fat) of cream ( $\mathbf{\Lambda})$ for each month in the period January 1998 to December 2000.

allowed can be achieved by addition of $2 \mathrm{X} \mathrm{MF}$ retentate. If the cheesemaking equipment is modified to allow a higher yield per $100 \mathrm{lb}$ standardized milk, then $3 \mathrm{X} \mathrm{MF}$ will start to become beneficial when the vats can handle more than a $2 \mathrm{X} \mathrm{MF}$ concentrate as standardized milk. Since $100 \mathrm{lb}$ unconcentrated raw milk yield approximately $9.3 \mathrm{lb}$ Cheddar cheese, benefit from $3 \mathrm{X} \mathrm{MF}$ is expected when the cheesemaking equipment is modified to allow a cheese yield higher than $18.6 \mathrm{lb}$ per 100 lb standardized milk.

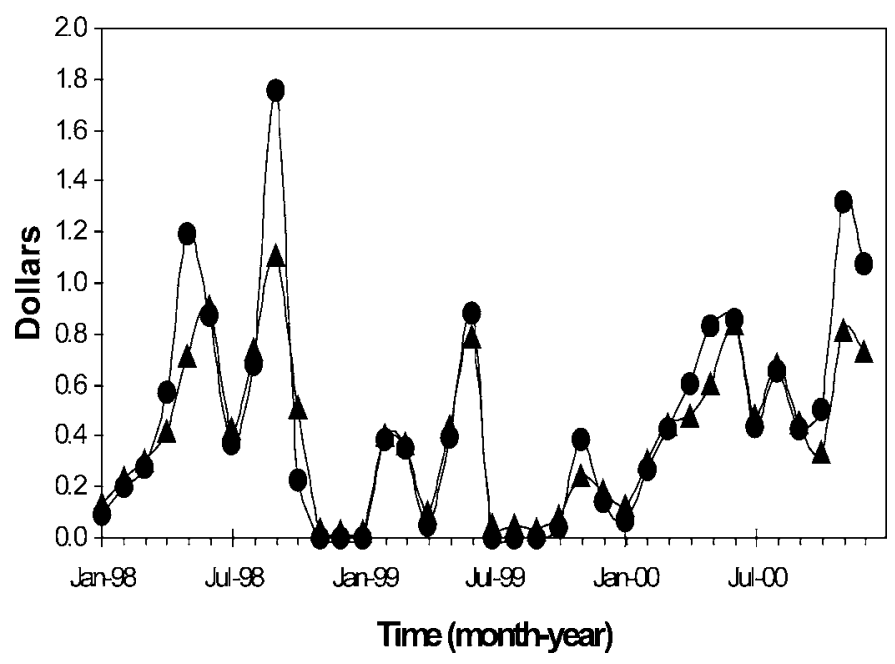

Figure 2. Benefit in net revenue (dollars/100 lb standardized milk) from microfiltration (versus conventional cheesemaking) for Cheddar (A) and mozzarella ( ) for each month in the period January 1998 to December 2000.

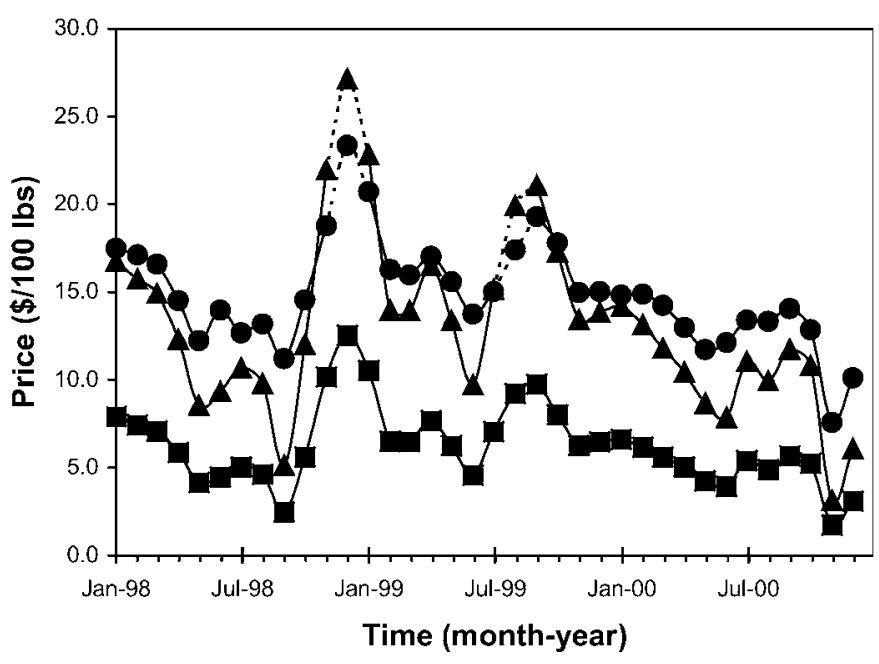

Figure 3. Price of nonfat portion of raw milk ( $\square$ ), price of $2 \mathrm{X}$ microfiltration (MF) retentate (purchased from another plant) required to achieve the same net revenue as the use of $2 \mathrm{X} \mathrm{MF}$ in the cheese plant prior to cheesemaking ( $\mathbf{\Delta})$, and price of the $2 \mathrm{X} \mathrm{MF}$ retentate (purchased from another plant) required so that the use of $2 \mathrm{X} \mathrm{MF}$ retentate produces the same net revenue as the use of conventional resources (-) for each month in the period January 1998 to December 2000. The dotted lines connect the months in which the use of MF did not lead to a higher net revenue compared to conventional cheesemaking.

Estimation of the price of $M F$ retentate. For both Cheddar and mozzarella, the price of $2 \mathrm{X}$ MF retentate purchased from another plant that would achieve the same net revenue as the production and use of $2 \mathrm{X} \mathrm{MF}$ retentate in the cheese plant was on average $\$ 13.17 \pm$ 5.35 per $100 \mathrm{lb}$ in the 3-year period studied (Figure 3). The average price of MF retentate that would make its use achieve the same net revenue as conventional resources, was $\$ 14.90 \pm 3.00$ per $100 \mathrm{lb}$ for Cheddar and $\$ 15.58 \pm 3.38$ per $100 \mathrm{lb}$ for mozzarella (Figure 4). This means that a mozzarella plant can pay a higher price than a Cheddar plant to purchase MF retentate and still increase net revenue from its use. For both cheeses the price of MF retentate purchased from another factory (y, in dollars per $100 \mathrm{lb}$ retentate) required to achieve the same net revenue as the use of MF in the cheese plant prior to cheesemaking varied proportionally to the value of the nonfat portion of raw milk $(\mathrm{x}$, in dollars per $100 \mathrm{lb})$ in each month:

$$
\mathrm{y}=2.2254 \times \mathrm{x}-0.6669, \mathrm{R}^{2}=0.9991
$$

\section{Problem 2. Comparison of Conventional vs. MF Cheesemaking Based on Manufacturing Costs}

Since $2 \mathrm{X}$ MF allows the production of twice as much cheese per day, MF markedly reduces the production 


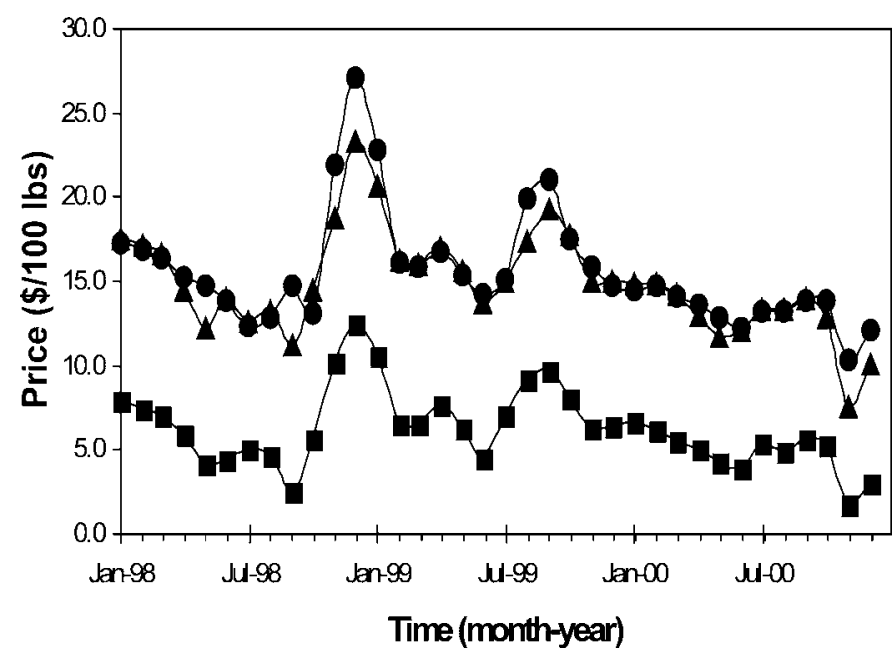

Figure 4. Price of nonfat portion of raw milk ( $\square$ ), and price of $2 \mathrm{X}$ microfiltration $(\mathrm{MF})$ retentate (purchased from another plant) required so that the use of $2 \mathrm{X} \mathrm{MF}$ retentate produces the same net revenue as the use of conventional resources, for Cheddar $(\boldsymbol{\Delta})$ and mozzarella ( for each month in the period January 1998 to December 2000 .

cost per pound of cheese due to economies of scale. This cost was estimated from the individual cost items of conventional cheese production (Mesa-Dishington et al., 1987), assuming that the fixed costs (supervisory and direct fixed labor and laboratory materials) were reduced by $50 \%$, while the cost items directly related to the amount of cheese produced (e.g., packaging costs) remained unchanged (Table 4). The cost items that increase but less than proportionally with the amount of cheese (e.g., utility costs) were assumed to decrease between 0 and $50 \%$. The same concept was applied to estimate the ultrafiltration cost for SPC production (Table 5) and the cost of MF of skim milk (Table 6) based on the production cost of WPC.

The yields and manufacturing costs of Cheddar cheese and coproducts for conventional and MF cheesemaking at a plant capacity of $1,920,000 \mathrm{lb}$ raw milk per day on a basis of $200 \mathrm{lb}$ raw milk are shown in Table 7. The production cost of MF cheddar was estimated to be 12.23 cents per pound of cheese. This is lower than the production cost of the same plant using the same volume of unfortified raw milk (16.70 cents per pound of cheese). The cost per pound of cheese for the MF Cheddar is similar to the production cost for a conventional plant of Cheddar with double capacity running unfortified raw milk (12.50 cents per pound of cheese). However, despite the lower cost of cheese production for the MF plant, the additional cost from MF of skim milk and the higher unit cost for WPC production (i.e., 37.3 vs. 30.0 cents per pound) resulted in a higher man- ufacturing cost for the MF plant compared to the conventional plant ( 363.51 vs. 336.60 cents per $200 \mathrm{lb}$ raw milk, respectively). The unit cost of WPC production was higher for the MF Cheddar plant because its WPC plant was operating at about half capacity compared to the WPC plant of the conventional Cheddar plant. Nevertheless, since SPC price may be higher than WPC price and the recovery of lactose from SPC production is expected to be higher than the recovery of lactose from WPC production, MF may be more attractive than conventional cheesemaking under certain conditions. It was desired to identify the relationships between those prices and recoveries that render MF profitable. First of all, two extreme cases were examined.

\section{No advantage in lactose recovery}

Given the yields estimated by the model (Table 7), $\mathrm{MF}$ is more profitable than conventional cheesemaking if the prices of products (i.e., $\mathrm{P}_{\text {Cheddar }}=$ price of Cheddar, $\mathrm{P}_{\mathrm{WPC}}=$ price of $34 \% \mathrm{WPC}$, and $\mathrm{P}_{\mathrm{SPC}}=$ price of $\mathrm{SPC}$ ) satisfy the relationship:

$$
\begin{gathered}
18.6 \times \mathrm{P}_{\text {Cheddar }}+2.09 \times \mathrm{P}_{\mathrm{WPC}}+1.38 \times \mathrm{P}_{\mathrm{SPC}}-3.6351> \\
18.6 \times \mathrm{P}_{\text {Cheddar }}+3.47 \times \mathrm{P}_{\mathrm{WPC}}-3.3660
\end{gathered}
$$

which yields $\mathrm{P}_{\mathrm{SPC}}>\mathrm{P}_{\mathrm{WPC}}+0.195$.

Thus, the price of SPC should be at least $\$ 0.195 / \mathrm{lb}$ higher than that of WPC to render MF more profitable than conventional cheesemaking.

\section{No advantage in SPC price}

The recovery of lactose from SPC production should exceed the recovery of lactose from WPC production $(62 \%)$ in order to outweigh the higher manufacturing cost of MF. The left hand side in the inequality below is the benefit in net revenue from the higher lactose recovery from SPC production, which depends on the price of lactose $\left(\mathrm{P}_{\mathrm{LAC}}\right)$ and the cost of waste processing $\left(\mathrm{C}_{\mathrm{WAS}}\right)$.

$$
\begin{gathered}
(\mathrm{LPREC} 2 / 0.62-1) \times 4.60 \\
\times\left(\mathrm{P}_{\mathrm{LAC}}+\mathrm{C}_{\mathrm{WAS}}\right)>3.6351-3.3660
\end{gathered}
$$

Assuming that the price of lactose powder equals its average value in the 3-year period from 1998 to 2000 $\left(\mathrm{P}_{\mathrm{LAC}}=\$ 0.186 / \mathrm{lb}\right)$ and the cost of waste handling is $\$ 0.05 / \mathrm{lb}$, the above condition yields:

\section{LPREC2 > 77\%}

Thus, the recovery of lactose from the UF permeate from SPC production should be at least $77 \%$ (vs. $62 \%$ from separated whey) to render MF profitable, assuming that the prices of SPC and WPC are equal. The two cases examined above are just two extreme cases, i.e., each one assumes only one advantage. However, there 
Table 4. Average manufacturing costs for conventional Cheddar cheese, not including the cost of raw milk, (Mesa-Dishington et al., 1987) and estimates of average manufacturing costs for Cheddar when 2X microfiltration (MF) is used.

\begin{tabular}{|c|c|c|c|c|c|}
\hline \multirow[b]{2}{*}{ Cost item } & \multicolumn{2}{|c|}{$\begin{array}{l}\text { Conventional cheese making } \\
\text { (100 lb of unconcentrated } \\
\text { milk in cheese vat) }\end{array}$} & \multirow{2}{*}{$\begin{array}{l}\text { Change in cost } \\
\text { when } 2 \mathrm{X} \text { MF } \\
\text { is used relative } \\
\text { to conventional }^{2}\end{array}$} & \multicolumn{2}{|c|}{$\begin{array}{l}2 \mathrm{X} M F \text { prior to cheese } \\
\text { making (100 lb of } 2 \mathrm{X} \mathrm{MF} \\
\text { retentate in cheese vat) }\end{array}$} \\
\hline & $\begin{array}{l}\text { Cost per lb } \\
\text { of cheese }{ }^{1} \\
\text { (cents) }\end{array}$ & $\begin{array}{l}\text { Percentage } \\
\text { of total costs }\end{array}$ & & $\begin{array}{l}\text { New cost per } \\
\text { lb of cheese } \\
\text { (cents) }\end{array}$ & $\begin{array}{l}\text { Percentage } \\
\text { of total costs }\end{array}$ \\
\hline \multicolumn{6}{|l|}{ Labor } \\
\hline Supervisory & 0.50 & 3.0 & $50 \%$ decrease & 0.25 & 2.0 \\
\hline Direct fixed & 0.60 & 3.6 & $50 \%$ decrease & 0.30 & 2.5 \\
\hline Direct variable & 5.80 & 34.7 & $35 \%$ decrease & 3.80 & 31.1 \\
\hline Total labor & 6.90 & 41.3 & & 4.35 & 35.6 \\
\hline \multicolumn{6}{|l|}{ Capital costs } \\
\hline Depreciation / interest & 2.30 & 13.8 & $20 \%$ decrease & 1.85 & 15.1 \\
\hline \multicolumn{6}{|l|}{ Utilities } \\
\hline Electricity & 0.20 & 1.2 & $30 \%$ decrease & 0.14 & 1.1 \\
\hline Fuel & 1.20 & 7.2 & $30 \%$ decrease & 0.84 & 6.9 \\
\hline Sewage & 0.10 & 0.6 & $30 \%$ decrease & 0.07 & 0.6 \\
\hline Total utilities & 1.50 & 9.0 & & 1.05 & 8.6 \\
\hline \multicolumn{6}{|l|}{ Materials } \\
\hline Laboratory & 0.10 & 0.6 & $50 \%$ decrease & 0.05 & 0.4 \\
\hline Production & 2.90 & 17.3 & $25 \%$ decrease & 2.18 & 17.8 \\
\hline Packaging & 1.20 & 7.2 & $0 \%$ change & 1.20 & 9.8 \\
\hline Cleaning & 0.50 & 3.0 & $50 \%$ decrease & 0.25 & 2.0 \\
\hline Total materials & 4.70 & 28.1 & & 3.68 & 30.0 \\
\hline Repair and maintenance & 0.20 & 1.2 & $0 \%$ change & 0.20 & 1.6 \\
\hline Property tax/insurance & 0.70 & 4.2 & $0 \%$ change & 0.70 & 5.7 \\
\hline Production inventory & 0.20 & 1.2 & $0 \%$ change & 0.20 & 1.6 \\
\hline Other expenses & 0.20 & 1.2 & $0 \%$ change & 0.20 & 1.6 \\
\hline TOTAL & 16.70 & 100.0 & & 12.23 & 100.0 \\
\hline
\end{tabular}

\footnotetext{
${ }^{1}$ The average cost per $\mathrm{lb}$ of cheese corresponds to plants with a capacity of 960,000 lb of milk per day, operating $21 \mathrm{~h}$ per day, and $6 \mathrm{~d}$ per week.

${ }^{2}$ Based on plant utilization.
}

are many combinations of SPC price and lactose recovery from SPC production that render MF more profitable than conventional cheesemaking. For every unit percent that lactose recovery from SPC production is higher than from WPC production, the required SPC price to render MF profitable decreases by $\$ 0.013 / \mathrm{lb}$ (from $\$ 0.195 / \mathrm{lb}$ higher than WPC price). For instance, if the recovery of lactose from the UF permeate from SPC production is $63 \%$, then the SPC price must be $\$ 0.182 / \mathrm{lb}$ higher than WPC price. The overall condition that should be satisfied to render MF profitable is:

$$
\mathrm{P}_{\mathrm{SPC}}-\mathrm{P}_{\mathrm{WPC}}>0.195-1.3 \times(\text { LPREC2 }-0.62)
$$

\section{Balance between increased net revenues and higher manufacturing costs}

It should be stressed that the above conditions do not take into account the benefit from MF on the ingredient cost, which was demonstrated in problem 1 and was on average $\$ 0.41$ per $100 \mathrm{lb}$ standardized milk for Cheddar, using $\mathrm{MF}$ retentate for supplementation of raw milk to produce the equivalent of a $1.25 \mathrm{X} \mathrm{CF}$ of standardized milk. If a full $2 \mathrm{X} \mathrm{MF}$ retentate could be used as $100 \%$ of the standardized milk in the cheese vat, which would be achieved by raising the maximum cheese yield allowed to about $19 \mathrm{lb}$ per $100 \mathrm{lb}$ standardized milk, then the net revenue advantage of MF cheesemaking would increase to about $\$ 1.15$ per $100 \mathrm{lb}$ standardized milk for the 3-year period (data not shown). Since the manufacturing cost of MF Cheddar was higher than the manufacturing cost of conventional Cheddar by only $\$ 0.27$ per $200 \mathrm{lb}$ raw milk (Table 7), which translates to $\$ 0.135$ per $100 \mathrm{lb}$ raw milk, the benefit of MF on the ingredient cost appears to be more than adequate to offset the higher manufacturing cost of MF cheesemaking.

\section{CONCLUSIONS}

The nonlinear optimization model presented in this paper is an enhanced version of a model described previously (Papadatos et al., 2002) that allows the option of MF of milk prior to cheesemaking while it also accounts for the coproducts produced from the MF permeate. The results of this study demonstrate the potential of this model to evaluate new technologies in cheese 
Table 5. 34\% Whey protein concentrate (WPC) manufacturing $\operatorname{costs}^{1}$ (Hurst et al., 1990) and estimates of $34 \%$ serum protein concentrate (SPC) ultrafiltration (UF) manufacturing costs based on $34 \%$ WPC costs.

\begin{tabular}{|c|c|c|c|c|}
\hline Cost item & $\begin{array}{l}\text { Cost per lb } \\
\text { of WPC }{ }^{1} \\
\text { (cents/lb WPC) }\end{array}$ & $\begin{array}{l}\text { Percentage } \\
\text { of total costs }\end{array}$ & $\begin{array}{l}\text { Change in ultrafiltration } \\
\text { costs to produce } \\
\text { SPC (relative to WPC) }\end{array}$ & $\begin{array}{l}\mathrm{UF} \text { cost for SPC } \\
\text { production } \\
\text { (cents/lb SPC) }\end{array}$ \\
\hline \multicolumn{5}{|l|}{ Labor } \\
\hline Supervisory & 1.2 & 3.1 & $0 \%$ change & 1.20 \\
\hline Direct fixed & 0.9 & 2.5 & $0 \%$ change & 0.90 \\
\hline Direct variable & 10.0 & 26.6 & $30 \%$ decrease & 7.00 \\
\hline Total labor & 12.1 & 32.2 & & 9.10 \\
\hline \multicolumn{5}{|l|}{ Capital costs } \\
\hline Depreciation/interest & 10.9 & 29.0 & $0 \%$ change & 10.9 \\
\hline \multicolumn{5}{|l|}{ Utilities } \\
\hline Electricity & 0.3 & 0.9 & $30 \%$ decrease & 0.21 \\
\hline Fuel & 5.7 & 15.2 & $30 \%$ decrease & 4.00 \\
\hline Sewage & 0.4 & 1.2 & $0 \%$ change & 0.40 \\
\hline Total utilities & 6.4 & 17.2 & & 4.60 \\
\hline \multicolumn{5}{|l|}{ Materials } \\
\hline Production & 0.3 & 0.9 & $0 \%$ change & 0.30 \\
\hline Packaging & 1.0 & 2.8 & $0 \%$ change & 1.00 \\
\hline Cleaning & 1.0 & 2.8 & $0 \%$ change & 1.00 \\
\hline Total materials & 2.3 & 6.4 & & 2.30 \\
\hline Repair and maintenance & 1.9 & 5.1 & $0 \%$ change & 1.90 \\
\hline Property tax/insurance & 3.4 & 9.1 & $0 \%$ change & 3.40 \\
\hline \multicolumn{5}{|l|}{ Production inventory } \\
\hline Other expenses & 0.3 & 0.9 & $0 \%$ change & 0.30 \\
\hline TOTAL & 37.3 & 100.0 & & 32.50 \\
\hline
\end{tabular}

${ }^{1}$ The average cost per pound of WPC serving a cheese plant with a capacity of 960,000 pounds of milk per day, operating $21 \mathrm{~h}$ per day, and $6 \mathrm{~d}$ per week.

${ }^{2}$ Conversion from MF permeate to $34 \%$ SPC.

Table 6. Estimates of processing costs for microfiltration of skim milk into $34 \%$ serum protein concentrate (SPC) production based on the ultrafiltration costs for $34 \%$ whey protein concentrate (WPC) production.

\begin{tabular}{ll}
\hline & $\begin{array}{l}\text { MF cost for SPC } \\
\text { production }\end{array}$ \\
(cents/lb of SPC) \\
(by comparison \\
with UF cost for \\
SPC production)
\end{tabular}

${ }^{1}$ Production of MF retentate and permeate. manufacture and improve decision making and profitability in the cheese industry.

The model demonstrated that MF prior to cheesemaking produced a higher net revenue in 30 out of the 36 mo in the period 1998 to 2000 for both Cheddar and low-moisture, part-skim mozzarella. The use of MF increased net revenue, compared to conventional cheesemaking, by $\$ 0.41$ for Cheddar and $\$ 0.45$ for mozzarella per $100 \mathrm{lb}$ standardized milk. The economic benefit from MF was greater in the months in which the cream price was high. While maximizing cheese yield was optimal in only half of the months for conventional Cheddar manufacture, it was optimal in all months for MF Cheddar manufacture. Therefore, the economic benefit from MF may be even further enhanced through improved plant efficiency. There was no additional benefit from a higher CF (3X) MF, since it gave the same net revenue as the $2 \mathrm{X} \mathrm{MF}$.

Although MF cheesemaking exhibited lower cost of cheese production than conventional cheesemaking, the MF Cheddar plant had higher total manufacture cost because of the additional cost of MF of skim milk and the higher unit cost of WPC production due to the lower capacity of the WPC plant in the MF Cheddar plant. However, the benefit in net revenue from $2 \mathrm{X}$ MF $(\$ 1.15$ per $100 \mathrm{lb}$ raw milk for Cheddar) was higher than the difference in manufacturing costs $(\$ 0.135$ per $100 \mathrm{lb}$ raw milk). Even if this benefit from MF was neglected, 
Table 7. Yields of Cheddar cheese and coproducts, amount of waste, manufacturing costs per pound of cheese, whey protein concentrate (WPC), and serum protein concentrate (SPC) for conventional Cheddar and MF Cheddar and total manufacturing cost for conventional and MF Cheddar.

\begin{tabular}{|c|c|c|c|c|}
\hline & \multicolumn{2}{|c|}{ Capacity 960,000 lb raw milk per day } & \multicolumn{2}{|c|}{ Capacity $1,920,000$ lb raw milk per day } \\
\hline Cheese: $18.60 \mathrm{lb}$ & 16.70 & 310.62 & 12.50 & 232.50 \\
\hline WPC: $3.47 \mathrm{lb}$ & 37.30 & 129.43 & 30.00 & 104.10 \\
\hline Lactose: $4.60 \mathrm{lb}$ & $\ldots$ & $\ldots$ & $\ldots$ & . . \\
\hline Total Cost & \multicolumn{4}{|c|}{ Capacity $960,000 \mathrm{lb} 2 \mathrm{X}$ standardized milk per day } \\
\hline \multicolumn{5}{|c|}{ MF Cheddar from $200 \mathrm{lb}$ milk } \\
\hline Cheese: $18.60 \mathrm{lb}$ & 12.23 & 227.48 & & \\
\hline WPC: $2.09 \mathrm{lb}$ & 37.30 & 77.96 & & \\
\hline SPC: $1.38 \mathrm{lb}$ & $42.08^{2}$ & $58.07^{2}$ & & \\
\hline Lactose: $4.60 \mathrm{lb}$ & $\ldots$ & $\ldots$ & & \\
\hline
\end{tabular}

${ }^{1}$ For each product, total cost equals the amount of product multiplied by the manufacturing cost per pound of product.

${ }^{2}$ The cost per pound of SPC includes the cost of microfiltration of skim milk.

a $34 \%$ SPC price higher than $34 \%$ WPC price by 20 cents per pound would render MF more profitable than conventional cheesemaking. The same would be true if the recovery of lactose in lactose powder from SPC production was $77 \%$ (vs. $62 \%$ from WPC production).

\section{REFERENCES}

Barbano, D. M. 1996. Mozzarella cheese yield: Factors to consider. Pages 29-38 in Proc. Sem. Maximizing Cheese Yield. Center for Dairy Res., Univ. of Wisconsin, Madison.

Bech A. 1993. Characterizing ripening in UF-cheese. Int. Dairy J. 3:329-342.

Bender, F. E., A. Kramer, and G. Kahan. 1982. Linear programming and its applications in the food industry. Food Technol. 36(7):94-96.

Cheryan, M. 1998. Ultrafiltration and microfiltration handbook. University of Illinois, Urbana, Illinois.

Craig, K. L., J. P. Norback, and M. E. Johnson. 1989. A linear programming model integrating resource allocation and product acceptability for processed cheese products. J. Dairy Sci. 72:3098-3108.

Frontline Systems, Inc. 1999. Solver user's guide. Incline Village, NV.

Guu, Y. K., and R. R. Zall. 1992. Nanofiltration concentration effect on the efficacy of lactose crystallization. J. Food Sci. 57(3):735-739.

Hillier, F. S., and G. J. Lieberman. 1995. Introduction to Mathematical Programming. 2nd Ed. McGraw-Hill, Inc., New York, NY.

Horton, B. 1997. Microfiltration-where is it headed? Australian J. Dairy Technol. 52:73-75.
Huffman, L. M. 1996. Processing whey protein for use as a food ingredient. Food Technol. 50:49-52.

Hurst, S., R. D. Aplin, and D. M. Barbano. 1990. Whey powder and whey protein concentrate production technology, costs and profitability. Part 4 of a research effort on Cheddar cheese manufacturing, A. E. Res. 87-3, Dept. Agric. Res. Managerial Econ. Cornell Univ., Ithaca, NY.

Jameson, G., and J. Lelievre. 1996. Effects of whey proteins on cheese characteristics. Int. Dairy Federation Bulletin 313:3-8.

Kerrigan, G. L., and J. P. Norback. 1986. Linear programming in the allocation of milk resources for cheese making. J. Dairy Sci. $69: 1432-1440$.

Lucey, J. A., and P. F. Fox. 1993. Importance of calcium and phosphate in cheese manufacture: A review. J. Dairy Sci. 76:1714-1724.

Maubois, J. 1997. Current uses and future perspectives of MF technology in the dairy industry. Int. Dairy Federation Bulletin 320:37-39.

Mesa-Dishington, J. K., D. M. Barbano, and R. D. Aplin. 1987. Cheddar cheese manufacturing costs: Economies of size and effects of different current technologies. Pages 1-86 in Dept. of Agric. Economics Res. Bulletin-A.E. Res. 87-3.

Mistry, V., and J. Maubois. 1993. Application of membrane separation technology to cheese production. Pages 493-522 in Cheese: Chemistry, physics and microbiology-general aspects. Vol. 1. P. Fox, ed. Chapman and Hall, London, UK.

Papadatos, A., A. M. Berger, J. E. Pratt, and D. M. Barbano. 2002. A nonlinear programming optimization model to maximize net revenue in cheese manufacture. J. Dairy Sci. 85:2768-2785.

Rosenberg, M. 1995. Current and future applications for membrane processes in the dairy industry. Trends in Food Sci. \& Technol. 6(1):12-19.

Samakidis I. 1994. Optimization of milk resource utilization in cheese production. M.S. Thesis, Dept. of Agric. Res. and Managerial Economics, Cornell Univ., Ithaca, NY. 